\title{
KLASIFIKASI UCAPAN KATA DENGAN SUPPORT VECTOR MACHINE
}

\author{
Sukmawati Nur Endah, Dinar Mutiara KN \\ Jurusan Ilmu Komputer/Informatika, FSM, Universitas Diponegoro \\ sukmane@yahoo.co.id, dinar.mutiara@undip.ac.id
}

\begin{abstract}
ABSTRAK
Menurut Undang-Undang No 32 Tahun 2002, Peraturan Komisi Penyiaran Indonesia No 02/P/KPI/12/2009 tentang Pedoman Perilaku Penyiaran dan Peraturan Komisi Penyiaran Indonesia No 03/P/KPI/12/2009 tentang Standar Program Siaran, diantaranya disebutkan bahwa program siaran tidak boleh memaki dengan kata-kata kasar, tidak boleh melecehkan, menghina atau merendahkan kelompok masyarakat minoritas dan marginal. Namun untuk mensensor kata-kata tersebut secara otomatis belum ada. Sehingga perlu adanya suatu perangkat lunak cerdas yang dapat menyensor kata-kata tersebut secara otomatis. Untuk dapat menyensor, perangkat lunak harus mampu mengenali kata-kata yang dimaksud. Penelitian ini mengusulkan pengklasifikasian ucapan kata dalam dua kelas, yaitu kelas kata-kata yang berisi makian kasar dan kelas kata yang bukan termasuk kata makian dengan menggunakan metode Support Vector Machine (SVM). Data ucapan kata yang diambil merupakan data suara untuk kelompok umur 19 - 21 tahun yang terdiri dari 19 pria dan 8 wanita. Masing-masing orang mengucapkan 25 kata makian kasar dan 25 kata yang bukan termasuk kata makian. Berdasarkan hasil eksperimen dengan melibatkan 25 data training dan 25 data testing, untuk suara pria menghasilkan tingkat keakuratan sebesar $78,4 \%$ dan untuk suara wanita menghasilkan tingkat keakuratan sebesar $80 \%$.
\end{abstract}

Kata kunci: Support Vector Machine, klasifikasi ucapan kata

\section{PENDAHULUAN}

Berdasarkan Undang-Undang No 32 Tahun 2002 tentang penyiaran, dalam pasal 4 disebutkan bahwa penyiaran sebagai kegiatan komunikasi massa mempunyai fungsi sebagai media informasi, pendidikan, hiburan yang sehat, kontrol dan perekat sosial [1]. Untuk memenuhi tujuan tersebut, isi siaran telah diatur dalam UndangUndang No 32 Tahun 2002 Pasal 35 dan Pasal 36 serta dipertegas di Peraturan Komisi Penyiaran Indonesia No 02/P/KPI/12/2009 tentang Pedoman Perilaku Penyiaran dan Peraturan Komisi Penyiaran Indonesia No 03/P/KPI/12/2009 tentang Standar Program Siaran. Dalam peraturan di atas, diantaranya disebutkan bahwa program siaran tidak boleh memaki dengan kata-kata kasar, tidak boleh melecehkan, menghina atau merendahkan kelompok masyarakat minoritas dan marginal seperti kelompok dengan pekerjaan tertentu (pekerja rumah tangga, hansip, satpam), kelompok yang memiliki penyimpangan (waria), kelompok dengan ukuran dan bentuk fisik di luar normal (gigi tongos, gemuk, cebol, mata juling), kelompok yang memiliki cacat fisik (tuli, buta, bisu), kelompok yang memiliki cacat atau keterbelakangan mental (autis, idiot), dan kelompok pengidap penyakit tertentu (HIV/AIDS, kusta, epilepsi, alzheimer, latah) [2,3].

Sampai saat ini, untuk program-program siaran yang tidak ditayangkan secara live (langsung), kata-kata makian yang kasar, melecehkan ataupun menghina akan disensor dengan memberikan suara bib pada kata-kata tersebut. Namun, untuk siaran langsung hal tersebut tidak dapat dilakukan. Hal ini merupakan kekhawatiran Komisi Penyiaran Indonesia (KPI) yang disampaikan oleh Nina Mutmainah, Anggota KPI Pusat yang merangkap Koordinator Isi Siaran dalam Diskusi KPI dengan Grup Trans Corp di Gedung Trans Corp, Senin, 13 Februari 2012 [4]. Untuk itu, diperlukan suatu perangkat lunak cerdas 
yang mampu mensensor kata-kata yang tidak diinginkan secara otomatis dan realtime. Supaya dapat mensensor kata-kata yang tidak diinginkan, perangkat lunak harus mampu mengenali terlebih dulu kata yang terucap termasuk kata-kata makian atau bukan. Salah satu cara untuk mengenali kata yang terucap, dapat dilakukan pengklasifikasian kata, apakah termasuk kata-kata makian atau bukan.

Dalam beberapa penelitian sebelumnya, metode untuk melakukan pengklasifikasian ada beberapa macam, diantaranya jaringan syaraf tiruan untuk klasifikasi data aplikasi kredit di bank dan data mining $[5,6]$, metode boosting untuk klasifikasi deteksi objek manusia [7], hidden markov model, Bayesian classification untuk klasifikasi dalam pengenalan suara [8], dan support vector machine untuk klasifikasi pose manusia [9,10]. Dari hasil penelitian tersebut, pengklasifikasian dengan support vector machine mempunyai tingkat keakuratan yang tinggi. Sehingga dalam penelitian ini dilakukan pengklasifikasian ucapan kata dalam dua kelas yaitu kelas kata-kata makian yang kasar yang perlu disensor, dan kelas yang bukan kata-kata makian, dengan menggunakan metode support vector machine.

\section{GAMBARAN UMUM SISTEM}

Gambaran umum sistem yang dibangun adalah seperti pada gambar 1 .

Tahap analisis suara merupakan tahap untuk mengambil nilai pitch dari ucapan kata yang telah direkam. Sedangkan untuk proses pengklasifikasiannya menggunakan metode SVM.

\section{SINYAL SUARA}

Definisi dari sinyal suara yaitu suatu sinyal yang mewakili dari suara [11]. Sinyal suara dibentuk dari kombinasi berbagai frekuensi pada berbagai amplitudo dan fasa. Untuk dapat melakukan proses pengolahan sinyal suara langkah pertama yaitu penyamplingan. Penyamplingan / pencuplikan adalah mengukur masukan sinyal suara pada sela waktu tertentu, kemudian mengkonversinya ke dalam skala tersendiri, dan menyimpannya. Gambar 2 menunjukkan sinyal suara yang dicuplik pada frekuensi $8 \mathrm{KHz}$. Ini berarti bahwa terjadi pengukuran masukan sinyal suara sebanyak 8000 kali selama 1 detik. Fungsi pencuplikan yaitu agar sinyal suara dapat disimpan dalam bentuk digital.

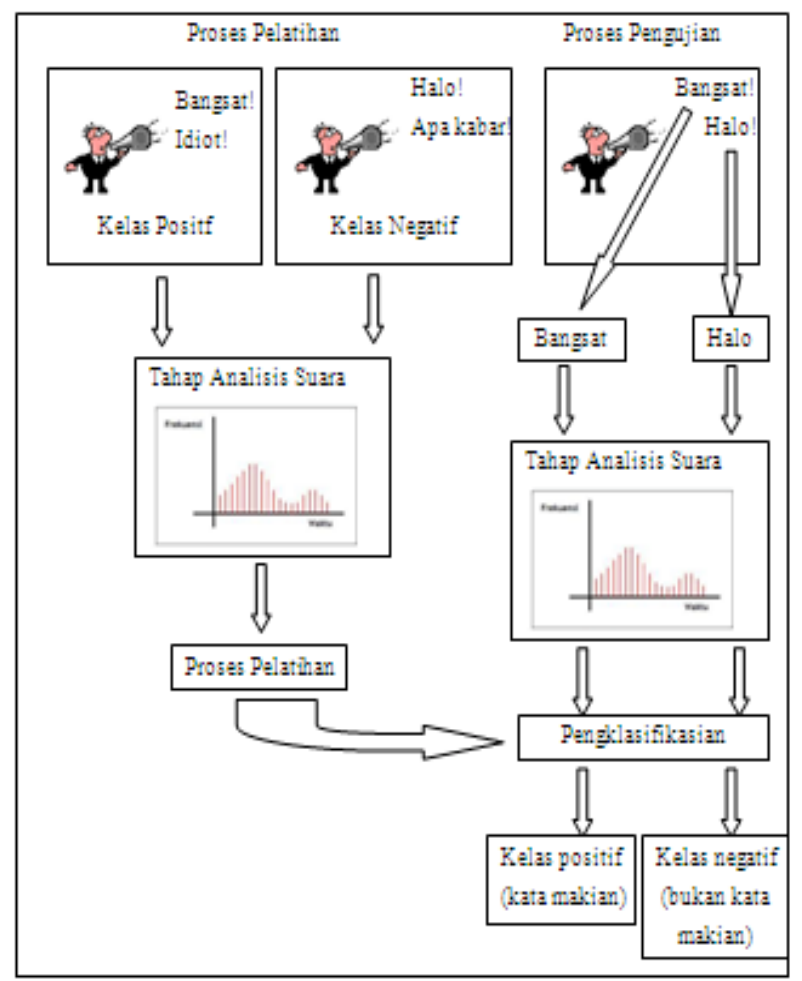

Gambar 1. Gambaran umum sistem

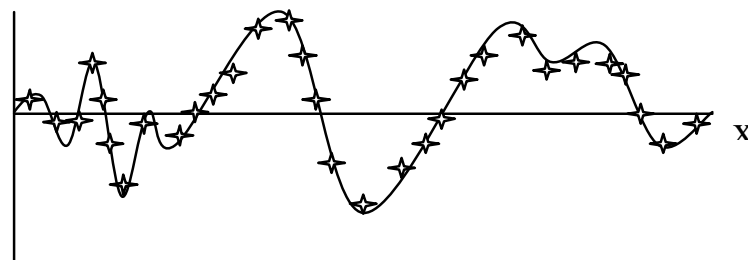

Gambar 2. Sinyal suara yang dicuplik pada frekuensi pencupikan $8 \mathrm{KHz}$ [11] 
Pada Gambar 3 menunjukkan sinyal suara yang sudah ditampilkan dalam bentuk digital, dimana bentuk sinyal bukanlah sinyal kontinyu tetapi merupakan sinyal diskret.

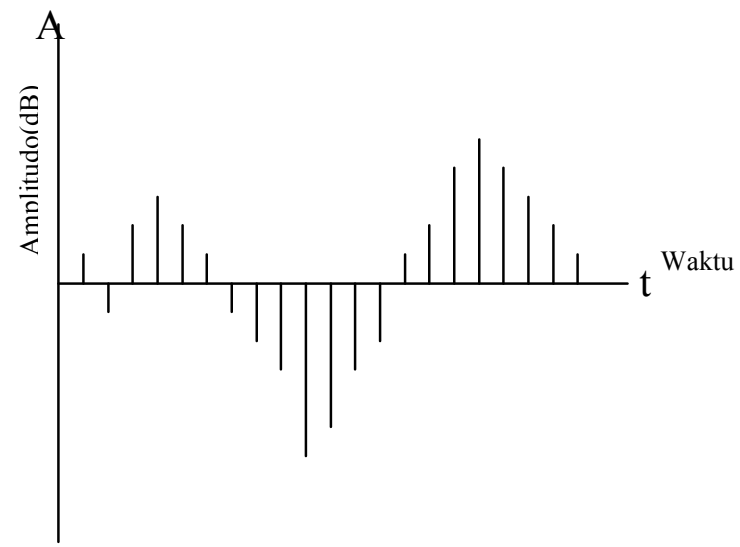

Gambar 3. Sinyal suara dalam bentuk diskret [11]

Menganalisis suatu suara dapat diartikan menganalisis suara dalam komponen frekuensi dan waktu dari suara tersebut. Komponen frekuensi menentukan tinggi rendahnya suara sedangkan komponen waktu sangat menentukan kapan suatu suara dibunyikan. Dengan mengetahui komponenkomponen tersebut sinyal suara dapat dianalisis dengan rinci.

Semua informasi isyarat analog agar tidak hilang setelah mengalami pencuplikan, maka proses pencuplikan tersebut harus mengikuti teorema pencuplikan, yaitu jika komponen frekuensi tertinggi didalam suatu sinyal adalah $\mathrm{f}_{\text {maks }}$, maka sinyal tersebut harus dicuplik pada frekuensi paling sedikit $2 \mathrm{f}_{\text {maks }}$ agar sampel dapat menggambarkan sinyal asli kembali secara penuh. Frekuensi cuplik dapat dinyatakan dengan $F_{s} \geq$ $2 \mathrm{f}_{\text {maks, }}$, dimana $\mathrm{Fs}$ adalah frekuensi pencuplikan atau disebut laju Nyquist. Oleh karena itu, jika komponen frekuensi maksimum dalam sinyal analog adalah $4 \mathrm{KHz}$, maka agar bisa mendapatkan semua informasi dalam sinyal tersebut, suara harus dicuplik dengan kecepatan frekuensi $8 \mathrm{KHz}$ atau lebih.

\section{PITCH}

Salah satu parameter dari sinyal suara adalah frekuensi fundamental. Frekuensi fundamental dalam istilah instrumen musik dikenal sebagai pitch atau nilai frekuensi dari suatu jenis nada. Pitch atau tinggi nada [12] adalah hasil akustik dari kecepatan getaran pita suara. Semakin cepat getaran pita suara, semakin tinggi, tinggi nadanya. Sehingga pitch ini dapat digunakan sebagai ciri bersuara.

Dengan melihat pemodelan untuk sintesa sinyal suara pada Gambar 4, generator impuls memberikan sumber pembangkitan untuk sinyal suara berbunyi berupa fonem vokal $(\mathrm{a} / \mathrm{e} / \mathrm{i} / \mathrm{o} / \mathrm{u})$ yang dapat diatur selang waktunya oleh parameterparameter periode pitch. Berdasarkan penelitian, periode pitch berkisar antara 10-20 milidetik [13]. Disamping generator impuls, generator derau acak juga berfungsi sebagai sumber pembangkitan untuk sinyal suara tidak bersuara berupa fonem konsonan $(\mathrm{h} / \mathrm{k} / \mathrm{s} / \mathrm{t})$.

Setiap manusia mempunyai kisaran pitch tersendiri, tergantung dari bentuk pangkal tenggorok yang dimilikinya[13]. Untuk pria memiliki kisaran pitch sebesar 50-250 Hz. Dan untuk wanita memiliki kisaran pitch sebesar 120$500 \mathrm{~Hz}$. Tinggi rendahnya nilai pitch tergantung pada intonasi suara, dan tingkat emosi dari manusia [13].

\section{SVM}

Support Vector Machine (SVM) dikembangkan oleh Boser, Guyon, Vapnik dan pertama kali dipresentasikan pada tahun 1992 di Annual Workshop on Computational Learning Theory. Konsep SVM dapat dijelaskan secara sederhana sebagai usaha mencari hyperplane terbaik yang berfungsi sebagai pemisah dua buah kelas pada input space [15]. Hyperplane dalam ruang vector berdimensi $d$ adalah affine subspace berdimensi $d-l$ yang membagi ruang vector tersebut ke dalam dua bagian yang masing-masing berkorespondensi pada kelas yang berbeda [16]. 


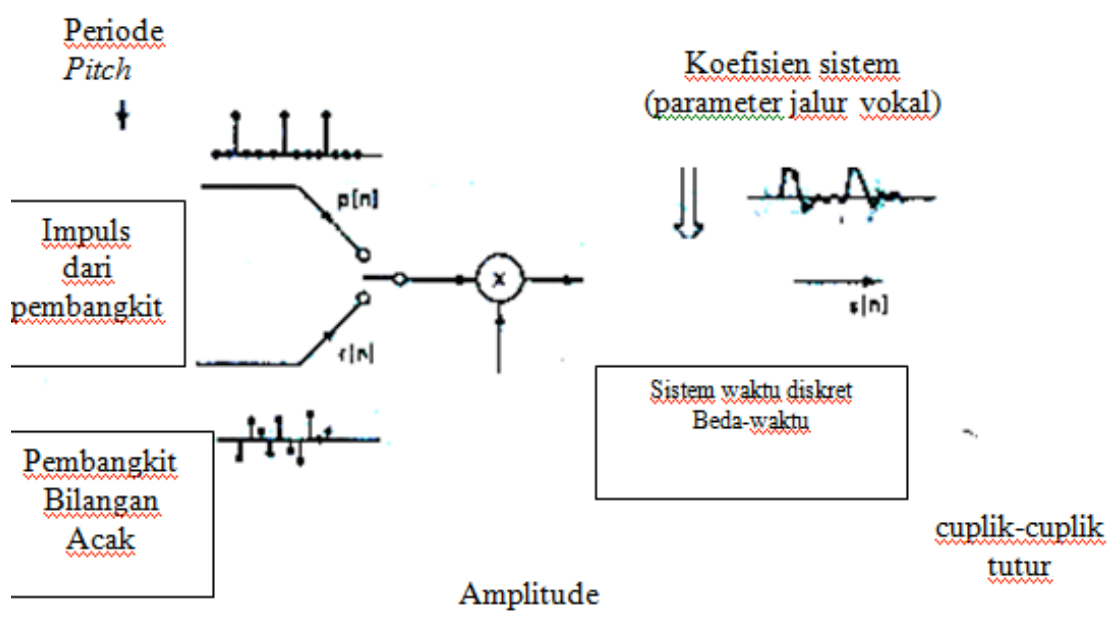

Gambar 4. Model sintesis suara [14]

Masalah klasifikasi merupakan usaha menemukan garis (hyperplane) yang memisahkan suatu objek dalam dua kelas. Seperti contoh pada Gambar 5 terlihat banyak kemungkinan garis klasifikasi linier yang dapat digunakan untuk memisahkan data, akan tetapi hanya ada satu garis yang memaksimalkan margin (jarak maksimum antara data terdekat pada setiap kelas). Garis klasifikasi linier tersebut dinamakan hyperplane pemisah yang optimal [17].

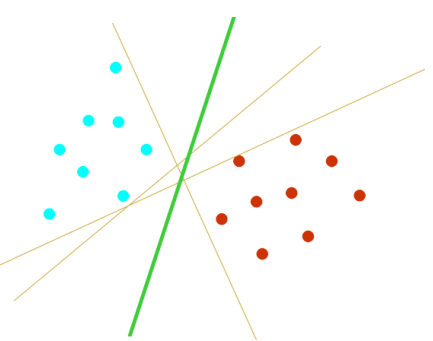

Gambar 5. Hyperplane pemisah yang optimal (Garis yang tebal)

Hyperplane pemisah terbaik antara kedua kelas dapat ditemukan dengan mengukur margin hyperplane tersebut dan mencari titik maksimalnya. Margin adalah jarak antara hyperplane tersebut dengan pattern terdekat dari masing-masing kelas. Pattern yang terdekat ini disebut dengan support vector. Garis solid pada Gambar 6 menunjukkan hyperplane yang terbaik, yaitu yang terletak tepat pada tengah-tengah kelas kedua kelas. Sedangkan titik merah dan kuning yang berada dalam lingkaran hitam adalah support vector. Usaha untuk mencari lokasi hyperplane ini merupakan inti dari proses pembelajaran pada SVM [15].

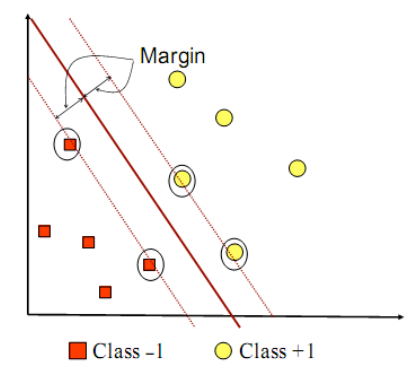

Gambar 6. Usaha SVM dalam menemukan hyperplane terbaik

Klasifikasi dengan metode SVM melibatkan data training dan data testing dimana masingmasing terdiri dari beberapa masukan data. Masing-masing masukan dalam data training berisi satu nilai target dan beberapa atribut. Tujuan dari SVM adalah memproduksi sebuah model yang dapat memprediksi nilai target dari data pengujian yang hanya diberikan nilai atributnya.

Jika diberikan himpunan data pelatihan $\left(\mathrm{x}_{\mathrm{i}}, \mathrm{y}_{\mathrm{i}}\right), \mathrm{i}=1,2, \ldots l$ dimana $\mathrm{x}_{\mathrm{i}} \in \mathrm{R}^{\mathrm{n}}$ dan $\mathrm{y} \in\{-1,1\}^{l}$, SVM membutuhkan solusi dari problem optimasi berikut, 


$$
\begin{aligned}
& \min _{\mathbf{w}, b, \boldsymbol{\xi}} \quad \frac{1}{2} \mathbf{w}^{T} \mathbf{w}+C \sum_{i=1}^{l} \xi_{i} \\
& \text { subject to } \quad y_{i}\left(\mathbf{w}^{T} \phi\left(\mathbf{x}_{i}\right)+b\right) \geq 1-\xi_{i} \\
& \xi_{i} \geq 0
\end{aligned}
$$

Disini vektor pelatihan $\mathrm{x}_{\mathrm{i}}$ dipetakan ke dimensi yang lebih tinggi dengan suatu fungsi $\phi$. Kemudian SVM akan mencari sebuah hyperplane yang memisahkan secara linier dengan margin maksimal dalam dimensi yang lebih tinggi tersebut. $\mathrm{C}>0$ merupakan parameter pinalti dari error. Selanjutnya, $\mathrm{K}\left(\mathrm{x}_{i}, \mathrm{x}_{j}\right)=\phi\left(\mathrm{x}_{i}\right)^{\mathrm{T}} \phi\left(\mathrm{x}_{j}\right)$ disebut fungsi kernel. Fungsi kernel ini ada beberapa macam, diantaranya fungsi linier, polynomial, radial basis function (RBF) dan sigmoid. [18]

- linier: $K\left(x_{i}, x_{j}\right)=x_{i}{ }^{T} x_{j}$

- polynomial: $K\left(x_{i}, x_{j}\right)=\left(\gamma x_{i}{ }^{T} x_{j}+r\right)^{d}, \gamma>0$.

- radial basis function (RBF): $K\left(x_{i}, x_{j}\right)=\exp \left(-\gamma\left\|x_{i}-x_{j}\right\|^{2}\right)^{d}, \gamma>0$.

- sigmoid: $K\left(x_{i}, x_{j}\right)=\tanh \left(\gamma x_{i}^{T} x_{j}+r\right)$

Dalam penelitian ini digunakan fungsi kernel yang linier yaitu $\mathrm{K}\left(\mathrm{x}_{i}, \mathrm{x}_{j}\right)=\mathrm{x}_{i}{ }^{\mathrm{T}} \mathrm{x}_{j}$.

\section{EKSPERIMEN DAN ANALISA HASIL}

\subsection{Eksperimen}

Eksperimen dilakukan dengan merekam suara 27 orang usia 19-21 tahun yang terdiri dari 19 pria dan 8 wanita. Perekaman dilakukan dengan rata-rata frekuensi sampling $44100 \mathrm{~Hz}$, channel mono dan resolusi 16 bit. Tiap orang mengucapkan 25 (lima) kata kasar dan 25 ( lima) kata tidak kasar.

Eksperimen yang dilakukan dibedakan untuk suara pria dan wanita. Masing-masing kategori suara dilakukan pengujian sebanyak 5 kali untuk data training dan data testing yang sama yaitu masing-masing 25 data dan sebanyak 2 kali untuk jumlah data training dan data testing yang berbeda. Setiap eksperimen mempunyai data kata yang berbeda. Data yang digunakan sebagai data training juga berbeda dengan data yang digunakan untuk data testing. Kelas positif merupakan kelas untuk kata-kata makian yang kasar, sedangkan kelas negatif merupakan kelas untuk kata yang bukan makian. Tabel 1 merupakan hasil eksperimen dengan jumlah data training sama dengan data testing, yaitu 25 data, sedangkan Tabel 2 merupakan hasil eksperimen dengan jumlah data training tidak sama dengan data

\begin{tabular}{|c|c|c|c|c|c|c|c|c|c|}
\hline \multirow[t]{2}{*}{ Suara } & \multirow[t]{2}{*}{ Eksperimen } & \multicolumn{3}{|c|}{ Data Training } & \multicolumn{3}{|c|}{ Data Testing } & \multirow{2}{*}{$\begin{array}{c}\text { Jumlah } \\
\text { Data Error }\end{array}$} & \multirow{2}{*}{$\begin{array}{c}\text { Tingkat } \\
\text { Keakuratan }(\%)\end{array}$} \\
\hline & & $\mathrm{K}+$ & $\mathrm{K}-$ & $\Sigma$ & $\mathrm{K}+$ & $\mathrm{K}-$ & $\Sigma$ & & \\
\hline \multirow[t]{6}{*}{ Wanita } & 1 & 12 & 13 & 25 & 13 & 12 & 25 & 6 & $76 \%$ \\
\hline & 2 & 13 & 12 & 25 & 12 & 13 & 25 & 3 & $88 \%$ \\
\hline & 3 & 12 & 13 & 25 & 13 & 12 & 25 & 5 & $80 \%$ \\
\hline & 4 & 13 & 12 & 25 & 12 & 13 & 25 & 7 & $72 \%$ \\
\hline & 5 & 12 & 13 & 25 & 13 & 12 & 25 & 4 & $84 \%$ \\
\hline & & \multicolumn{7}{|c|}{ Rata-rata } & $80 \%$ \\
\hline \multirow[t]{2}{*}{ Suara } & Eksperimen & \multicolumn{3}{|c|}{ Data Training } & \multicolumn{3}{|c|}{ Data Testing } & Jumlah & Tingkat \\
\hline & & $\mathrm{K}+$ & $\mathrm{K}-$ & $\Sigma$ & $\mathrm{K}+$ & $\mathrm{K}-$ & $\Sigma$ & Data Error & Keakuratan $(\%)$ \\
\hline \multirow[t]{6}{*}{ Pria } & 1 & 12 & 13 & 25 & 13 & 12 & 25 & 5 & $80 \%$ \\
\hline & 2 & 13 & 12 & 25 & 12 & 13 & 25 & 1 & $96 \%$ \\
\hline & 3 & 13 & 12 & 25 & 12 & 13 & 25 & 6 & $76 \%$ \\
\hline & 4 & 13 & 12 & 25 & 12 & 13 & 25 & 7 & $72 \%$ \\
\hline & 5 & 12 & 13 & 25 & 13 & 12 & 25 & 8 & $68 \%$ \\
\hline & & \multicolumn{7}{|c|}{ Rata-rata } & $78,4 \%$ \\
\hline
\end{tabular}
testing.

Tabel 1. Hasil eksperimen dengan jumlah data training dan data testing sama 
Tabel 2. Hasil eksperimen dengan jumlah data training dan data testing tidak sama

\begin{tabular}{|c|c|c|c|c|c|c|c|c|c|}
\hline \multirow[t]{2}{*}{ Suara } & \multirow[t]{2}{*}{ Eksperimen } & \multicolumn{3}{|c|}{ Data Training } & \multicolumn{3}{|c|}{ Data Testing } & \multirow{2}{*}{$\begin{array}{c}\text { Jumlah } \\
\text { Data Error }\end{array}$} & \multirow{2}{*}{$\begin{array}{c}\text { Tingkat } \\
\text { Keakuratan (\%) }\end{array}$} \\
\hline & & $\overline{\mathrm{K}+}$ & K - & $\bar{\Sigma}$ & $\overline{\mathrm{K}+}$ & $\mathrm{K}-$ & $\Sigma$ & & \\
\hline \multirow[t]{2}{*}{ Wanita } & 1 & 5 & 5 & 10 & 20 & 20 & 40 & 11 & $72,5 \%$ \\
\hline & 2 & 20 & 20 & 40 & 5 & 5 & 10 & 2 & $80 \%$ \\
\hline \multirow[t]{2}{*}{ Pria } & 1 & 5 & 5 & 10 & 20 & 20 & 40 & 3 & $92,5 \%$ \\
\hline & 2 & 20 & 20 & 40 & 5 & 5 & 10 & 2 & $80 \%$ \\
\hline
\end{tabular}

\subsection{Analisa Hasil}

Dari tabel 1 terlihat bahwa rata-rata untuk suara pria menghasilkan tingkat keakuratan sebesar 78,4\% dan untuk suara wanita menghasilkan tingkat keakuratan sebesar $80 \%$. Adanya error dalam pengklasifikasian ini kemungkinan disebabkan oleh adanya data-data nilai pitch yang bernilai 0 . Nilai 0 pada pitch dapat terjadi karena salah pemotongan kata pada saat proses perekaman ucapan kata. Dalam hal ini kata dipotong lebih maju untuk beberapa waktu sebelumnya. Sehingga frekuensi awal yang didapat adalah frekuensi sebelum seseorang berbicara.

Tingkat keakuratan pada suara wanita untuk data training yang lebih kecil dari data testing lebih rendah dibanding tingkat keakuratan untuk data training yang lebih semakin besar dari data testing. Hal ini karena semakin banyak data training, SVM semakin dapat membentuk hyperplane dengan sempurna. Kondisi yang ada kebalikan dengan data suara pria. Ini disebabkan karena atribut suara pria lebih banyak dari pada suara wanita.

\section{KESIMPULAN}

Berdasarkan pembahasan sebelumnya dapat disimpulkan bahwa metode SVM dapat digunakan untuk mengklasifikasikan ucapan kata yang termasuk kata-kata makian dan kata yang bukan makian dengan tingkat keakuratan yang tinggi, yaitu berkisar 72\% - 95\%. Tinggi nada atau nilai pitch suatu ucapan kata dapat digunakan sebagai ciri atau atribut untuk proses pengklasifikasian. Hasil penelitian ini dapat digunakan untuk membuat sebuah sistem cerdas otomatisasi penyensor ucapan kata makian yang kasar.

\section{DAFTAR PUSTAKA}

[1] Soekarnoputri, M (Presiden RI). 2002. Undang-Undang No 32 Tahun 2002 Tentang Penyiaran. Lembaran Negara Republik Indonesia Tahun 2002 No 139. Jakarta

[2] Sendjaja, S.D. (Ketua Komisi Penyiaran Indonesia Pusat). 2009. Peraturan Komisi Penyiaran Indonesia No 02/P/KPI/12/2009 tentang Pedoman Perilaku Penyiaran. Jakarta

[3] Sendjaja, S.D. (Ketua Komisi Penyiaran Indonesia Pusat). 2009. Peraturan Komisi Penyiaran Indonesia No 03/P/KPI/12/2009 tentang Standar Program Siaran. Jakarta

[4] RG. 2012. Diskusi KPI-Trans Corp: Hindari Tayangan Sensitif, http://www.kpi.go.id/index.php?option=com content\&view $=$ article $\&$ id $=30378 \% 3$ Akpihindari-tayangansensitif\&catid $=14 \% 3$ Adalam-negeriumum\&lang=id, 7 Maret 2012

[5] Dhauswara, G dan V.S Moertini. 2004. Jaringan Syaraf Tiruan Propagasi Balik untuk Klasifikasi Data. Integral. FMIPA Unpar. Vol 9 No 3, Nov 2004

[6] Maharani, W. 2009. Klasifikasi Data Menggunakan JST Back Propagation Momentum dengan Adaptive Learning Rate. Seminar Nasional Informatika 2009 (Semnas IF 2009), UPN Veteran Yogyakarta, 23 Mei 2009. ISSN 1979-2328

[7] Fatihah, C,. 2007. Tesis : Metode Boosting dengan Fungsi Pengklasifikasi Dasar Kernel untuk Deteksi Objek Manusia. Universitas Indonesia. Jakarta

[8] Fung, P, and Roth, D,. 2005. Guest Editor Introduction:Machine Learning in Speech and Language Technologies. Springer Science+Bussiness Media. Netherland 
[9] Widyanto, M.R., Endah, S.N, and Hirota, K., 2010. Human Behavior Classification Using Thinning Algorithm and Support Vector Machine. Journal of Advanced Computational Intelligence and Intelligent Informatics. Volume 14 No. 1 Page 28-34, Januari 2010, ISSN 1343-0130, Jepang

[10] Endah, S.N, dan Widyanto, M.R,. 2008. Klasifikasi Pose Skeleton Manusia dengan Menggunakan Support Vector Machine. Jurnal Ilmu Komputer dan Informasi, Volume 1 Nomer 2 Halaman 27-30, Juni 2008, ISSN 1979-0732. Fasilkom UI

[11] Wismono, R. Yudhi, 2002. Identifikasi Jenis Tingkatan Suara Manusia Dengan Metode Real Cepstrum, Teknik Elektro Universitas Diponegoro, Semarang, 2002.

[12] Chaer,Abdul, 1994. Linguistik Umum, Cetakan Pertama, Penerbit PT. Rineka Cipta, Jakarta.

[13] Deller Jr, John R., dan Proakis, John G., 1993. Discrete - Time Processing of Speech Signal, Mac Millan Pubhlising Company, New York.
[14] Oppenheim, Alan V., 1998. Digital Signal Processing, Prentice-Hall of India.

[15] Nugroho, A.S., Witarto, A.B, Handoko, D., Application of Support Vector Machine in Bioinformatics, Proceeding of Indonesian Scientific Meeting in Central Japan, December 20, 2003, Gifu-Japan

[16] Cristianini N., Taylor J.S., An Introduction to Support Vector Machines and Other KernelBased Learning Methods, Cambridge Press University, 2000

[17]Gunn, Steve R,. 1998. Technical Report: Support Vector Machine for Classification and Regression. Faculty of Engineering, Science and Mathematics, University of Southampton, 14 May 1998

[18] Hsu, C., Chang, C., and Lin, C., 2008. A Practical Guide to Support Vector Classification. Department of Computer Science, Natural Taiwan University, Taiwan 
